\title{
Rare is frequent and frequent is costly: rare diseases as a challenge for health care systems
}

\author{
J.-Matthias Graf von der Schulenburg • \\ Martin Frank
}

Published online: 30 October 2014

(C) Springer-Verlag Berlin Heidelberg 2014

\section{Why are rare diseases important and difficult to handle?}

Of 30,000 known diseases about 6,000-7,000 are defined as rare diseases, also commonly known as orphan diseases [1]. Within the European Union (EU), rare diseases are specified as indications with a prevalence of less than 5 out of 10,000 [2]. In other jurisdictions, different critical prevalence rates prevail when it comes to the classification of rare diseases: the United States (US) 7.5, Japan 4 and Australia 1.2 patients per 10,000 in a population [3]. Although the number of patients in each rare disease indication is low, the aggregated number of patients living with a rare disease is large. Many of them do not know that they are affected by a rare disease and are still searching for a diagnosis or therapy. In total, the prevalence of all rare diseases is approximately $5 \%$, which equals, for instance, about half of the prevalence of diabetes. Therefore, experts assume that 400 million people worldwide are rare-disease patients. Focusing on the EU, 27-36 million people suffer from rare diseases. Within the USA, there is an estimated prevalence of approximately 25 million US citizens [4]. Only within Germany, approximately 4 million patients suffer from a rare disease [5]. This adds up to a paradox of rarity. Many rare diseases are associated with a significant negative effect on life expectancy and quality of life. As a considerable number of those diseases are caused by gene mutations, many patients are children suffering from a hereditary disease. Treating patients with

J.-M. Graf von der Schulenburg $(\bowtie) \cdot$ M. Frank

Center for Health Economics Research Hannover, Leibniz

University Hannover, Königsworther Platz 1, 30167 Hannover, Germany

e-mail: jms@ivbl.uni-hannover.de rare diseases is not uncommon for physicians. However, in many cases, care providers are not aware of the fact that they are medicating a rare disease.

Rare diseases are mostly but not always hereditary diseases. Many infections are widely prevalent in some parts of the world but rare in others. There are some rare types of cancer, too. One of the most common rare diseases is cystic fibrosis (CF) or mucoviscidosis. It is very rare in Asia but has a prevalence of 5 out of 10,000 in Europe's population. $\mathrm{CF}$ is a complex lifelong chronic disease caused by genetic mutations. In most cases, multiple organ systems are affected. In the 1950s, life expectancy for children with CF was only a few months. Today, the average median survival for patients with $\mathrm{CF}$ has increased to 3-5 decades. In Germany, with a total population of 83 million people, there are about 8,000 patients living with $\mathrm{CF}$. In contrast, there is one disease, ribose-5-phosphate isomerase deficiency, which has only been diagnosed a single time, so that it is the rarest genetic disease on earth. This makes clear why it is not appropriate to formulate general statements on rare diseases. In the following editorial, economic challenges caused by rare diseases are discussed. In addition, four actual research projects on rare diseases are presented, and conclusions stated.

\section{Rare diseases from an economic point of view}

In Richard Musgrave's famous article "The Voluntary Exchange Theory of Public Economy" [6], published in 1939, he structured the responsibilities of a government into three major functions or "branches": the stabilization of the economy, the (re)distribution, and the achievement of an efficient allocation of resources. Transferring this conceptual division of the responsibilities of governments 
to the health care system, we see, from an economic point of view, three major tasks for health care systems: the health care system should provide stable, appropriate and high-quality care to the patients in the country (stabilization). People should have equal access to health care facilities. Those who have the largest needs should be prioritized. The financing scheme of the health care system should be in line with the equity values of the society (distribution). Health services should produce health outcomes efficiently, and the resources used in medical care should be used in order to maximize the wellbeing of the patients (allocation). These are precisely the economic challenges for all health policies in countries around the world, and apply in particular to the treatment of rare diseases.

\section{Challenges for health care systems posed by rare diseases}

From a dual economic and organizational point of view, rare diseases are the cause of a number of challenges for health care systems:

1. In many cases, the diagnosis of rare diseases is difficult and time-consuming, because the majority of physicians have little or no experience with those diseases. As a consequence, educational efforts and better information systems supporting physicians and informing patients are needed. On their way to a diagnosis, some patients undergo an odyssey through the health care system, often getting neither the correct treatment nor a name for their sickness. Accelerated diagnostics could reduce health-related sufferings as well as the underuse and misuse of health care resources. In the future, novel diagnostic technologies based on genome sequencing methods will improve diagnoses. At this time, genome sequencing is still expensive.

2. Because the number of patients is small, the question is how to organize appropriate care for those patients. In particular, for patients with $\mathrm{CF}$ and some other rare indications, the German health care system offers specialized out-patient care units, mostly outside university medical centers, financed by the social health insurance system (SHI), to provide treatment for patients. It is always claimed that these centers are underfunded. In fact, there are not only medical reasons why $\mathrm{CF}$ patients are mostly treated in hospital-based special-care centers. A German study showed that treating those patients is economically uninteresting for for-profit hospitals and office-based physicians. The quarterly costs are about 500 euro without drugs, but the reimbursement is less than 250 euro [7]. Hence, a lot of these specialized care units are underfunded, and there are fewer economic incentives for hospitals to provide high-quality care for patients with rare diseases. Moreover, a study calculated mean annual outpatient costs for medication at 21,603 euro per patient [8]. These examples show why health care for people with rare diseases is costly, and that there are too few resources for treatment in some cases.

3. Is it more suitable to have only a few centers, or even only one center in each country or large region like the EU or the US, to serve those patients? Or is there a need for less specialized, but therefore more frequent, treatment centers closer to patients' homes? Crossborder health care provision is a challenge for health care systems in the EU, especially with regard to reimbursement of these services. Furthermore, there are additional challenges for the German health care system, which is constructed on the concept of federalism. The organization of health care for people with rare diseases is predominantly arranged by decentralized regional authorities, e.g., accreditations of specialized care centers for rare diseases are conducted by the regional health ministries of the federal states. However, the EU has developed criteria for the establishment and collaboration of European Reference Networks (ERNs) for rare diseases. Article 12 of Directive 2011/24/EU establishes the legal framework for creating a system of ERNs in the EU [9]. ERNs should be able to collaborate, coordinate and share their knowledge across borders to ensure efficiency of health systems and access to high-quality health care. Indeed, there is a lack of evidence with regard to efficient and validated models of organization and cross-border financing of complex networks such as ERNs.

4. In many cases, the treatment of rare diseases is extremely costly. One example is the inherited disorder Gaucher's disease, which can be treated with an enzyme replacement therapy. A model-based costeffectiveness analysis calculated lifetime costs of $5,716,473$ euro for a patient with type 1 Gaucher's disease in a Dutch setting. However, the treatment is extremely effective. Over an 85-year lifetime period, 55.86 QALYs (quality-adjusted life years) were gathered, resulting in a cost-effectiveness ratio of 884,994 euro per QALY [10]. Comparable results were shown for enzyme replacement therapies for patients with Fabry disease [11]. A study analyzed the budget impact of orphan drugs in Sweden and France from 2013 to 2020, using a dynamic forecasting model. Orphan drugs caused $2.7 \%$ in Sweden and $3.2 \%$ in France of total drug expenditure in 2013. A portion of $4.1 \%$ in Sweden and $4.9 \%$ in France was estimated 
by 2020 [12]. In particular, drug costs for payers are quite high due to the small number of patients treated and the unique position of the pharmaceutical companies offering orphan drugs. Society and payers have to decide, in a common effort, how willing they are to pay for rare disease treatment. As resources are limited, there is a macroeconomic allocation dilemma: if society spends more on the treatment of rare diseases, it leaves fewer resources for the treatment of more common diseases. Is it fair to spend large portions of the health care budget on small patient groups, and less money on large patient groups? This leads to a more general question: is the number of patients an adequate criterion for the allocation of public resources in medical care at all? Is there a suitable argument justifying the payment of extraordinarily high prices, just because of the rarity of a disease [13]?

5. It is expected that pharmaceutical companies will spend less money on drug research and development used in the treatment of patients with rare diseases, due to the market being limited and highly specialized, and the payback period of research costs being much longer than in broad indications as asthma, chronic obstructive pulmonary disease (COPD), diabetes, hypertension, coronary heart disease (CHD), depression and dementia. It is hypothesized that patients with rare diseases have been underserved by commercial drug development [14]. As a consequence, in many jurisdictions-among others in the EU and the USspecific legislations have been enacted to stimulate more research. In this regard, new drugs for rare diseases have been developed, which would not bepresenting the arguments-commercially viable otherwise. Today, the European Commission has designated 923 orphan medical products. Ninety drugs have had approval to be traded as orphan drugs in the EU [15]. However, revenues are generated by the quantity of sales of the drug as well as the price. One economic solution would be that the price-setting of orphan drugs should be free and available to an unrestricted market. However, utility and, moreover, cost-utility of a drug should be the basis for reimbursement. Following this idea, many countries have imposed a fourth hurdle for drugs: after the licensing of a drug, the payers' organization or a public institution decides on the pricing and reimbursement of drugs. For instance, Australia imposed such a fourth hurdle in 1987 with the Pharmaceutical Benefit Advisory Committee. It was followed by Canada in 1994 with the Patented Medicines Prices Review Board, and by the UK in 1999 with the National Institute for Health and Care Excellence (NICE). Last but not least, Germany introduced its fourth hurdle in 2011, splitting tasks between the Institute for Quality and Efficiency in Health Care (IQWiG), which conducts the assessment, and the Federal Joint Commission (G-BA), which grants the appraisal. As a particularity, in Germany, orphan drugs with a market turnover of less than 50 million euros are always assumed to have an additional benefit without any further proof being necessary. Economists may question whether this special status of orphan drugs is justified. Under the assumption of sound market mechanisms, higher prices for those drugs should compensate the supplier for fewer patients. In addition, the development of innovative treatments is much easier and more feasible in a very specific disease area, compared to a large one already overcrowded by therapy options.

6. In the event that price mechanisms do not provide sufficient incentives to encourage pharmaceutical companies to develop orphan drugs, another question needs to be raised. In tangible terms, there is a need to discuss the right regulations and incentives to stimulate a sufficient supply of treatment options-without overshooting - for patients with rare diseases. For instance: is it better to lower the requirements for the proof of efficacy, quality and safety, increase the price level, or subsidize research?

7. Another challenge is the avoidance of crowding-out effects: in the case that the treatment of patients with rare diseases is more profitable, if research on drugs for patients with rare diseases is highly subsidized and if it is easier for researchers to publish on rare indications, we will have fewer physicians treating patients with more common diseases, less research on drugs for a broader population and less scientific research on widespread diseases. Currently, $40 \%$ of the spending in biomedical research is allocated to research and development of cancer drugs [16]. Many of these cancer indications are rare diseases. A study for the German Federal Ministry of Health forecasted that within the following 5-7 years, probably 30-50 new cancer drugs will be approved in Europe [17]. Moreover, there are incentives for pharmaceutical companies to conduct "salami slicing" and to divide cancer indications into small orphan sections, often based on genetic discrepancies of the tumor, to use the benefits of the orphan drug legislation.

It is not surprising that rare diseases have been a heatedly debated topic among scientists, health policy-makers and payers. For instance, the EU initiated a lot of actions in the past few years in order to improve the treatment of patients with rare diseases. Among others, the EU initiated a concerted action plan called EUROPLAN (European 
Table 1 Importance of different health care aspects for patients with rare diseases

\begin{tabular}{|c|c|c|c|c|c|c|}
\hline \multicolumn{7}{|c|}{ How important are the following aspects of treatment of your rare disease? } \\
\hline$n=47$ & $\begin{array}{l}\text { Very important } \\
(\%)\end{array}$ & $\begin{array}{l}\text { Important } \\
(\%)\end{array}$ & $\begin{array}{l}\text { Neutral } \\
(\%)\end{array}$ & $\begin{array}{l}\text { Less important } \\
(\%)\end{array}$ & $\begin{array}{l}\text { Unimportant } \\
(\%)\end{array}$ & $\begin{array}{l}\text { No information } \\
(\%)\end{array}$ \\
\hline Close to home health care & 12.8 & 25.5 & 36.2 & 17.0 & 2.1 & 6.4 \\
\hline High level of expertise of the medical caregiver & 85.1 & 10.6 & 0.0 & 0.0 & 0.0 & 4.3 \\
\hline Timely appointment & 29.8 & 46.8 & 10.6 & 8.5 & 0.0 & 4.3 \\
\hline $\begin{array}{l}\text { Good cooperation between medical and non- } \\
\text { medical caregiver }\end{array}$ & 44.7 & 25.5 & 17.0 & 4.3 & 0.0 & 8.5 \\
\hline Good collaboration with family doctor & 46.8 & 38.3 & 6.4 & 4.3 & 0.0 & 4.2 \\
\hline Unchanging key contacts & 40.4 & 48.9 & 6.4 & 0.0 & 0.0 & 4.3 \\
\hline Early access to diagnostic tools & 42.6 & 40.4 & 4.3 & 4.3 & 4.3 & 4.1 \\
\hline Psychological care for patients and relatives & 51.1 & 34.0 & 8.5 & 2.1 & 0.0 & 4.3 \\
\hline Fast access to new drugs & 34.0 & 29.8 & 17.0 & 8.5 & 4.3 & 6.4 \\
\hline $\begin{array}{l}\text { Availability of specially trained non-medical } \\
\text { therapists }\end{array}$ & 42.6 & 29.8 & 19.1 & 2.1 & 0.0 & 6.4 \\
\hline Easy access to aid & 57.4 & 23.4 & 6.4 & 6.4 & 2.1 & 4.3 \\
\hline Information about new treatment options & 61.7 & 31.9 & 2.1 & 0.0 & 0.0 & 4.3 \\
\hline Information about treatment centers & 55.3 & 31.9 & 2.1 & 0.0 & 0.0 & 10.7 \\
\hline Access of treatment options outside Germany & 12.8 & 21.3 & 36.2 & 12.8 & 10.6 & 6.3 \\
\hline Others & 0.0 & 0.0 & 6.4 & 0.0 & 0.0 & 93.6 \\
\hline
\end{tabular}

Project for Rare Diseases National Plans Development). In addition, the European Commission founded an expert committee for rare diseases, EUCERD (European Union Committee of Experts on Rare Diseases), which gives its advice to the commission. One recommendation was the implementation/initiation of national concerted action plans in all EU member states. The US has imposed an Orphan Drug Act, which covers both rare diseases and nonrare diseases "for which there is no reasonable expectation that the cost of developing and making available in the US a drug for such disease or condition will be recovered from sales in the US of such drug" [18]. Currently, there is an ongoing debate on orphan drug policies and the reimbursement of orphan drugs [13, 14, 19, 20]. The question remains: what are the costs and benefits of worldwide activities ushered in to increase the awareness of rare diseases and to provide incentives to spend more on research and development of treatments for patients with rare diseases?

\section{Approaches for better health care for patients with rare diseases}

In the following paragraphs, we report about three German and one European research project to improve the treatment of patients with rare diseases.

In a research project for the Federal Government of Germany, patients with rare diseases were asked what they considered as important for an appropriate treatment of their disease. The most important factor was the competence of the physician, followed by excellent information and easy access to medical appliances. Moreover, the patients pointed to the fact that it is mostly unimportant for them whether the treatment centers are close to their homes; if necessary, they can arrange access for treatment outside the country [5]. Table 1 shows the importance of different health care aspects for patients with rare diseases.

Based on this study, the German Federal Ministry of Health convened a round table in 2010, called NAMSE (National Action Plan for People with Rare Diseases). In NAMSE, 28 different key bodies and organizations of the German health care system discussed a road map to improve the situation for patients with rare diseases [21]. The results were summarized in a national action plan, which was published and approved by the German Federal Government in August 2013 [22]. It includes 52 policy proposals.

ZIPSE [23] and se-atlas [24], launched in 2013, are projects based on the German plan of action for people with rare diseases. The aim of the ZIPSE project [23] is to conceptualize and realize a central information portal about rare diseases. With this, the health and well-being of people with rare diseases should be improved. The portal itself should not contain primary information, but should refer to existing information sources, such as Orphanet (www. orpha.net). In addition, the project team should create a user guide for relevant and appropriate sources of 
information. For that, a comprehensive evaluation regarding the information demand of patients as well as care providers will be conducted by qualitative research studies. Furthermore, the benefits and costs of the portal will be evaluated. ZIPSE brings together various stakeholders and experts. It consists of three single projects. The first one deals with the theoretical concept of a central portal. Moderated workshops will be conducted to gather information about, e.g., relevant information providers or quality criteria for information sources. The second project will evaluate information demands by conducting interviews with the target groups (patients as well as care providers). Thereupon, reference routines for targeting group-specific bundles of information from primary sources are created. A prototype of a central web-based information portal shall be implemented in the third project.

The project se-atlas [24] started in June 2013 and is scheduled to be completed by May 2015. The goal of the project se-atlas is to focus on an innovative representation of medical care options for people with rare diseases in Germany, derived from the Orphanet data set. In addition to the name and address of an institution, information like the rare disease treated, individual contact data including telephone numbers, opening hours, etc. is also stored. Data will be presented in both the format of an interactive map and a detailed listing. The project is intended to help complete the existing data set and to improve accessibility by enhancing search functions and by testing new ways of interaction in order to keep the data relevant and up to date. Potential users of the information platform are patients and their relatives, practitioners, non-medical personnel and the general public. Based on the search term entered and the estimated or provided location of the user, information on relevant expert centers will be presented by the website, in the form of a map and a detailed listing. The user should be able to filter the presented health care providers by different criteria such as distance, specification and quality. The goal is to provide a fast and intuitive overview about the different facilities.

Psychosocial care and coordinated teamwork by different care providers are especially important for patients with rare diseases. The VEMSE study analyses the utilities and costs of a multi-professional team approach, including psychosocial services in German CF patients. Evidence from prospective controlled trials supporting this comprehensive approach, regarding the effect on medical, psychosocial and economic outcomes, is lacking. The aim of VEMSE is to investigate the effect of a care program integrating medical and psychosocial interventions into the quality of care for $\mathrm{CF}$ patients in the German health care system. One hundred fifty-one $\mathrm{CF}$ patients aged 6 years or older were recruited in three $\mathrm{CF}$ out-patient clinics and will be followed up for 2 years. Three hundred patients from other CF centers, receiving usual care and matched for sex, age and lung-function, were identified as controls. Patients in the intervention group were offered a program based on individual treatment agreements (ITA) between patient/ care-giver and CF physician. ITAs focus on patient-specific goals and may include medical, nutritional, and/or physiotherapeutic measures. In addition to current center standards, expert exercise counseling, patient education and psychosocial interventions were provided when necessary. ITAs are supported by external case-managers. The primary efficacy criterion is the quality of care, assessed by the frequency of BMI and lung-function measurements per year. Secondary criteria include a range of medical (e.g., mortality, lung-function, BMI) and psychosocial (quality of life, adherence, care-giver distress) parameters. In addition, the use of economic resources is assessed. The study commenced clinically in May 2012.

BURQOL-RD [25] is a 3-year project under the second Program of Community Action in the Field of Public Health. It commenced in April 2010 and is promoted by DG Sanco. The aim of BURQOL-RD is to generate a model to quantify the socio-economic costs and healthrelated quality of life (HRQOL), both for patients and for caregivers, for up to ten rare diseases in different European countries. This model will be adaptable and sufficiently sensitive to capture the differences in the distinct health and social care systems in the EU member states. The information generated by the BURQOL-RD consortium will help to:

1. Design future policies in the area of rare diseases, which will ultimately have positive benefits for EU citizens' health, both that of patients and of their caregivers. Readily transfer the protocols established to other RDs and to other countries.

2. Compare the availability and access to specific health resources for specific RDs in each country.

3. Explore the potential relationships between $\mathrm{HRQL}$ and access to healthcare resources.

\section{Conclusion}

From an economic point of view, the health care system should achieve the following goals: efficient production of health care, just distribution of resources and stable financing. The current intensive discussion on rare diseases demonstrates the difficulty in achieving all three goals at the same time. Rare diseases collectively are frequent. That is why they are an extraordinary financial and organizational challenge for payers. The treatment of patients with rare diseases is either very costly and/or extremely difficult. For many of those diseases, no effective therapy exists. 
Because the diseases are rare, incentives are needed to stimulate research for developing and maintaining appropriate treatments for those patients. However, resources spent on rare diseases either increase health care costs or lead to shortcomings in the provision of standard health care. To provide high-quality care and to meet patients' needs, a network of high-competence centers for patients with rare diseases must be developed in Europe. Moreover, a critical review of the reimbursement system is needed as well as the installation of information systems for the diagnosis and treatment of rare diseases for physicians and patients. In many countries, there is still a lack of highquality information on rare diseases. The EU has provided an umbrella regulation to improve the treatment for those patients. The example of Germany shows how governmental programs fill out those umbrella regulations and try to improve health care for patients with rare diseases. But the example also shows that it is not easy to adapt to the system overnight.

Acknowledgments No sources of funding were used to conduct this study or prepare this manuscript. The authors have no conflicts of interest that are directly relevant to this article.

\section{References}

1. Orphanet: about rare diseases. http://www.orpha.net/consor/cgibin/Education_AboutRareDiseases.php?lng=EN (2014). Accessed 2 May 2014

2. Regulation (EC) No 141/2000 of the European Parliament and of the Council of 16 December 1999 on orphan medicinal products. http://ec.europa.eu/health/files/eudralex/vol-1/reg_2000_141_cons2009-07/reg_2000_141_cons-2009-07_en.pdf (2009). Accessed 2 May 2014

3. Orphanet: What is an orphan drug? http://www.orpha.net/consor/ cgi-bin/Education_AboutOrphanDrugs.php?lng=EN\&stapage= ST_EDUCATION_EDUCATION_ABOUTORPHANDRUGS (2014). Accessed 2 May 2014

4. Kaplan, W., Wirtz, V., Mantel-Teeuwisse, A., Stolk, P., Duthey, B., Laing, R.: Priority medicines for Europe and the World 2013 update. World Health Organization, Department of Essential Drugs and Medicines Policy. http://ec.europa.eu/enterprise/sec tors/healthcare/files/docs/prioritymedicines_report_en.pdf (2013). Accessed 2 May 2014

5. Eidt, D., Frank, M., Reimann, A., Wagner, T.O.F., Mittendorf, T., Schulenburg, J.-M.: Maßnahmen zur Verbesserung der gesundheitlichen Situation von Menschen mit Seltenen Erkrankungen in Deutschland. A study for the German Federal Ministry of Health. http://www.gesundheitsforschung-bmbf.de/_media/Autorentexte_ Massnahmen-seltene-Krankheiten_200908.pdf (2009). Accessed 2 May 2014

6. Musgrave, R.A.: The voluntary exchange theory of public economy. Q J Econ 53, 213-237 (1939)
7. Eidt, D., Mittendorf, T., Wagner, T.O.F., Reimann, A., Schulenburg, J.-M.: Cost analysis for ambulatory treatment of cystic fibrosis in Germany. Overview of the prospective study results. Med Klin 104, 529-535 (2009)

8. Eidt-Koch, D., Wagner, T.O.F., Mittendorf, T., Schulenburg, J.M.: Outpatient medication costs of patients with cystic fibrosis in Germany. Appl Health Econ Health Policy 8, 11-118 (2010)

9. Article 12 of Directive 2011/24/EU of the European Parliament and of the Council of 16 March 2011 on the application of patients' rights in cross-border healthcare: criteria of European Reference Networks (ERN) http://ec.europa.eu/health/cross_bor der_care/docs/cons_implementation_ern_concept_paper_en.pdf (2011). Accessed 2 May 2014

10. Van Dussen, L., Biegstraaten, M., Hollak, C.E., Dijkgraaf, M.G.: Cost-effectiveness of enzyme replacement therapy for type 1 Gaucher disease. Orphanet J Rare Dis 9, 51 (2014)

11. Rombach, S.M., Hollak, C.E.M., Linthorst, G.E., Dijkgraaf, M.G.W.: Cost-effectiveness of enzyme replacement therapy for Fabry disease. Orphanet J Rare Dis 8, 29 (2013)

12. Hutchings, A., Schey, C., Dutton, R., Achana, F., Antonov, K.: Estimating the budget impact of orphan drugs in Sweden and France 2013-2020. Orphanet J Rare Dis 9, 22 (2014)

13. McCabe, C., Claxton, K., Tsuchiya, A.: Orphan drugs and the NHS: should we value rarity? Br Med J 331, 1016-1019 (2005)

14. Drummond, M.F., Wilson, D.A., Kanavos, P., Ubel, P., Rovira, J.: Assessing the economic challenges posed by orphan drugs. Int J Technol Assess Health Care 23, 36-42 (2007)

15. European commission: register of designated orphan medicinal products http://ec.europa.eu/health/documents/community-regis ter/html/alforphreg.htm (2014). Accessed 2 May 2014

16. Cutler, D.M.: Are we finally winning the war on cancer? J Econ Perspect 22, 3-26 (2008)

17. Glaeske, G., Höffken, K., Ludwig, W.-D., Schrappe, M., Weißbach, L., Wille, E.: Sicherstellung einer effizienten Arzneimittelversorgung in der Onkologie. A study for the German Federal Ministry of Health. http://www.bmg.bund.de/fileadmin/dateien/ Downloads/O/Onkologie/Gutachten_Sicherstellung_einer_effi zienten_Arzneimittelversorgung_in_der_Onkologie.pdf (2010). Accessed 2 May 2014

18. US Orphan Drug Act: http://www.fda.gov/regulatoryinformation/ legislation/federalfooddrugandcosmeticactfdcact/sig nificantamendmentstothefdcact/orphandrugact/default.htm (2014). Accessed 2 May 2014

19. Côte, A., Keating, B.: What is wrong with orphan drug policies? Value Health 15, 1185-1191 (2012)

20. Drummond, M.F., Towse, A.: Orphan drug policies: a suitable case for treatment. Eur J Health Econ 15, 335-340 (2014)

21. National action league for people with rare diseases: http://www. namse.de/english.html. Accessed 2 May 2014

22. National plan of action for people with rare diseases: action fields, recommendations, proposed actions. http://www.namse.de/ images/stories/Dokumente/Aktionsplan/national\%20plan\% 20of\%20action.pdf. Accessed 2 May 2014

23. Zentrales Informationsportal über seltene Erkrankungen: http:// www.portal-se.de/startseite.html. Accessed 2 May 2014

24. se-atlas-Kartierung von Versorgungsleistungen für Menschen mit Seltenen Erkrankungen: https://www.se-atlas.de/startseite/. Accessed 2 May 2014

25. BURQOL RD: http://www.burqol-rd.com/. Accessed 2 May 2014 